\title{
Effects of spatial fragmentation on the elevational distribution of bird diversity in a typical modern mountain
}

\author{
Wei Liu ${ }^{1}$, Haigen $\mathrm{Xu}^{2}$, Xiufen $\mathrm{Li}^{3}$, Dandan $\mathrm{Yu}^{1}$, and Jianfeng $\mathrm{Yi}^{1}$ \\ ${ }^{1}$ Nanjing Institute of Environmental Sciences \\ ${ }^{2}$ Nanjing Institute of Environmental Sciences, Ministry of Environmental Protection of \\ China \\ ${ }^{3}$ Taian Taishan Mountain Beauty Spot Management Committee
}

January 17, 2022

\begin{abstract}
The biodiversity in mountainous ecosystems is high but is threatened by rapid environmental change. Urbanization and other anthropogenic factors in the mountains surrounding cities can affect land use and spatial fragmentation. Moreover, patterns of habitat are closely related to elevation and have a major effect on montane biodiversity. The aim of this study was to analyze the effects of spatial fragmentation on the vertical distribution pattern of bird diversity by characterizing the structure of the bird community, species diversity, and landscape factors at different altitudes. From 2016 to 2019, this study made a four-years continuous monitoring of the breeding biric belts. The result indicated Mount Tai harbored a high bird diversity. Bird richness, abundance and Shannon-Wiener index decreased with latitude in Mount Tai. Moreover, the composition of bird communities varied along altitudinal gradients and supported some special species in different elevational bands. Road density, number of habitat patches, patch density, and the percentage of forest significantly affected bird diversity. The effect of patch density was higher compared with other landscape factors. Sufficient habitat and more patches in the low-mountain belt supported higher bird diversity. The middle-mountain belt and high-mountain belt showed contrasting patterns. Our results highlight the effects of ongoing urbanization and human activities on montane biodiversity and emphasize the need for artificial habitats in the mountains surrounding cities to be managed.
\end{abstract}

\section{Hosted file}

2022.1.10 Clean manuscript.docx available at https://authorea.com/users/398122/articles/ 552996-effects-of-spatial-fragmentation-on-the-elevational-distribution-of-birddiversity-in-a-typical-modern-mountain 